KOÇ UNIVERSITY-TÜSİAD ECONOMIC RESEARCH FORUM WORKING PAPER SERIES

\title{
UNDERSTANDING FINANCIAL CRISES: CAUSES, CONSEQUENCES, AND POLICY RESPONSES
}

\author{
Stijn Claessens \\ M. Ayhan Kose \\ Luc Laeven \\ Fabián Valencia
}

Working Paper 1301

January 2013 


\title{
Understanding Financial Crises: Causes, Consequences, and Policy Responses
}

\author{
Stijn Claessens, M. Ayhan Kose, Luc Laeven, and Fabián Valencia ${ }^{\Upsilon}$
}

\begin{abstract}
The global financial crisis of 2007-09 has led to an intensive research program analyzing a wide range of issues related to financial crises. This paper presents a summary of a forthcoming book, Financial Crises: Causes, Consequences, and Policy Responses, that includes 19 contributions examining these issues and distilling policy lessons. The book covers a wide range of crises, including banking, balance-of-payments, and sovereign debt crises. It reviews the typical patterns prior to crises, considers lessons on their antecedents, and analyzes their evolution and aftermath. It also provides valuable policy lessons on how to prevent, contain and manage financial crises.

JEL Classification Numbers: E32, F44, G01, E5, E6, H12.

Keywords: global financial crisis, sudden stops, debt crises, banking crises, currency crises, defaults, restructuring, welfare cost, asset price busts, credit busts, prediction of crises.
\end{abstract}

$\Upsilon$ International Monetary Fund. sclaessens@imf.org; akose@imf.org; 1laeven@imf.org; fvalencia@imf.org. This paper is based on the introduction chapter of the forthcoming book, Financial Crises: Causes, Consequences, and Policy Responses, edited by Stijn Claessens, M. Ayhan Kose, Luc Laeven, and Fabián Valencia, to be published by the International Monetary Fund. The views expressed in this paper are those of the authors and do not necessarily represent those of the IMF or IMF policy. 


\section{Introduction}

By now, the tectonic damage left by the global financial crisis of 2007-09 has been well documented. World per capita output, which typically expands by about 2.2 percent annually, contracted by 1.8 percent in 2009 , the largest contraction the global economy experienced since World War II. During the crisis, markets around the world experienced colossal disruptions in asset and credit markets, massive erosions of wealth, and unprecedented numbers of bankruptcies. Five years after the crisis began, its lingering effects are still all too visible in advanced countries and emerging markets alike: the global recession left in its wake a worldwide increase of 30 million in the number of people unemployed. These are painful reminders of why there is a need to improve our understanding of financial crises. This forthcoming book serves this purpose by bringing together a number of innovative studies on the causes and consequences of financial crises, and policy responses to them.

Although there is a rich literature on financial crises, there has been no publication since the recent financial crisis providing in one place a broad overview of this research and distilling its lessons. The forthcoming book fills this critical gap. It covers a wide range of crises, including banking, balance-of-payments, and sovereign debt crises. It reviews the typical patterns prior to crises and considers lessons on their antecedents, analyzes the evolution of crises and examines various policy responses-in terms of macroeconomic policies, restructuring of banks, households, financial institutions and sovereigns, and studies their aftermath - in terms of short- and medium-term growth impacts, and financial and fiscal consequences. It includes contributions from outstanding scholars working on financial crises and a select set of papers produced by researchers at the IMF. The forthcoming book's audience includes researchers, academics and graduate students working on financial crises. Since it shows how applied research can provide lessons, it is also an excellent source of reference for policy makers.

The remainder of this introduction is structured as follows: in Section II, a brief summary of similarities across crises is presented. Section III discusses differences across crises. Sections IV-IX present a detailed overview of the chapters of the forthcoming book. Section IV provides an overview of the various types of crises and introduces a comprehensive database 
of crises. Section V reviews the broad lessons on crisis prevention and management. Section VI discusses the short-run economic effects of crises, recessions and recoveries. Section VII analyzes the medium-term effects of financial crises on economic growth. Section VIII reviews the use of policy measures to prevent booms, mitigate busts, and avoid crises. Finally, Section IX reviews the policy measures to mitigate the adverse impact of crises and how to restructure banks, sovereigns, and households.

\section{Similarities across Crises}

As the forthcoming book documents, lessons from past crises are insightful since there are many similarities across crises episodes, even when the exact triggers for and timing of crises may vary. Although the relative importance of the sources of the current crisis will be debated for some time, the run-up to the current episode shares at least four major features with earlier episodes: rapid increases in asset prices; credit booms; a dramatic expansion in marginal loans; and regulation and supervision that failed to keep up with developments. Combined, these factors sharply increased the risk of a financial crisis, as they had in earlier episodes.

Asset Price Bubbles. While the specific sector experiencing a boom can vary across crises, asset price booms are common. This time it was house prices that sharply increased prior to the crisis, including in the U.S., the U.K., Iceland, Ireland, Spain and other markets that subsequently ran into problems. The patterns of house price increases are reminiscent of those in earlier major crises episodes. The overall size of the housing booms and their dynamicsincluding rising house prices in excess of 30 percent in the five years preceding the crisis and peaking prior to the beginning of the crisis - are remarkably similar to developments prior to previous banking crises in advanced economies, as observed by Reinhart and Rogoff (2008). These booms were generally fueled by fast rising credit resulting in sharply increased household leverage. As often before, the combination of rapid house prices increases and buildup in leverage turned out to be the most dangerous elements.

Credit Booms. As in most previous crises, the rapid expansion of credit played a large role in the run-up to the crises. Credit aggregates grew very fast in the U.K., Spain, Iceland, Ireland, 
and several Eastern European countries, often fueling real estate booms. Such episodes of rapid credit growth generally coincide, as they did again this time, with large cyclical fluctuations in economic activity. While aggregate credit growth was less pronounced, reflecting slower corporate credit expansion, household indebtedness in the U.S. rose rapidly after 2000, driven largely by increased mortgage financing, with historically low interest rates and financial innovation contributing. And in spite of low interest rates, debt service relative to disposable income reached historical highs.

While historically not all credit booms end up in a crisis, the probability of a crisis increases with a boom, especially the larger its size and the longer its duration. The mechanisms linking credit booms to crises include increases in the leverage of borrowers and lenders, and a decline in lending standards. In the recent episode, both channels were at work. Increased leverage, in part due to inadequate oversight, left households vulnerable to a decline in house prices, a tightening in credit conditions and a slowdown in economic activity. Not only did the correction harm consumers - as they ran into debt servicing problems, it also led to systemic risks. And default rates were higher where credit growth had been more rapid with this pattern extended to other countries caught in crises.

Marginal Loans and Systemic Risk. Credit booms or, more generally, rapid growths in financial markets, are often associated with a deterioration in lending standards. They often mean the creation of marginal assets which are viable as long as favorable economic conditions last. In the U.S. and elsewhere this time, a large portion of the mortgage expansion consisted of loans extended to borrowers with limited credit and employment histories, and often on terms poorly suited to the borrowers' conditions. Debt servicing and repayment were, hence, vulnerable to economic downturns and changes in credit and monetary conditions. This maximized default correlations across loans, generating portfolios highly exposed to declines in house prices - confirmed ex-post through high non-performing loans.

In other countries, the same pattern meant large portions of credit denominated in foreign currency. Such exposures had been common before, for example in the corporate and financial sectors before the Asian crisis of the late 1990s. In the current crisis, in several 
eastern European economies large portions of credit (including to households) were denominated in foreign currency (euros, Swiss francs, and yen). While interest rates lower than those on local currency loans increased affordability, borrowers' ability to service loans depended on continued exchange rate stability. Again, this meant high default risk correlations across loans and systemic exposure to macroeconomic shocks.

Risky liability structures of financial intermediaries typically add to vulnerabilities. The importance of wholesale bank funding, which in the past often took the form of foreign liabilities, especially in emerging market crises, manifested itself this time in the non-banking system, particularly in the U.S. Moreover, commercial banks and investment banks in many advanced countries sharply increased their leverage. On the back of buoyant housing and corporate financing markets, favorable conditions spurred the emergence of large-scale derivative markets, such as mortgage-backed securities and collateralized debt obligations with payoffs that depended in complex ways on underlying asset prices. The corporate credit default swap market also expanded dramatically due to favorable spreads and low volatility. The pricing of these instruments was often based on a continuation of increasing or high asset prices.

\section{Poorly designed liberalization, ineffective regulation and supervision, and poor} interventions. Crises often follow expansions triggered by badly sequenced regulatory reforms and financial liberalization. Poorly developed or regulated domestic financial systems have often ended up unable to intermediate large capital inflows effectively in the wake of capital account liberalizations. Deficiencies in oversight often led to currency and maturity mismatches and to large and concentrated credit risks. In the latest crisis, although perhaps in more subtle forms, regulatory approaches to and prudential oversight were insufficient as well to restrict excessive risk taking.

As in the past, financial institutions, merchant banks, investment banks and off-balance sheet vehicles of commercial banks operated - to varying degrees - outside of the regulatory and supervisory perimeter. The shadow banking system was able to grow without much oversight, eventually becoming a systemic risk. Swaths of derivative markets were largely unregulated 
and poorly overseen, creating the potential for chain reactions leading to systemic risk. International activities of financial institutions were not monitored properly. Market discipline was not effective in halting the buildup of systemic risks. Markets, rating agencies and regulators underestimated the conflict of interest and information problems associated with the originate-to-distribute model.

As happened in earlier episodes, prevention and early intervention mechanisms proved to be insufficient as well. Before the crisis, the focus of authorities remained primarily on the liquidity and insolvency of individual institutions, rather than on the resilience of the financial system as a whole. This led to an underestimation of the probability and costs of systemic risk. In addition, as has been common in previous episodes, interventions came late in many countries, contributing to significantly raising the real and fiscal costs, and hampering the post-crisis recovery. At the international level, insufficient coordination among regulators and supervisors and the absence of clear procedures for the provision of liquidity and the resolution of global financial institutions hindered efforts to prevent the cross-border transmission of the crisis.

\section{Differences across Crises}

Despite the similarities noted in the previous section, crises recur, in part as the antecedent to each batch of crises has its own unique features, making people think "this time is different" as succinctly described by Reinhart and Rogoff (2009). In addition to presenting a careful study of these similarities, the forthcoming book also covers the aspects that distinguish the current crisis from those of the earlier episodes. In particular, many chapters in the forthcoming book consider four major differentiating elements: benign macroeconomic conditions prior to the crisis; opaqueness of financial transactions and a large role of nonbanks; a high degree of international financial integration; and major roles played by advanced countries.

Remarkably benign macroeconomic conditions. One of the most significant differences was that the buildup of risks around the world occurred in a context of benign macroeconomic 
conditions in most countries, with solid economic growth, low inflation, and few financial crises. This created a sense of exuberance in financial markets and a feeling of accomplishment among policy makers. Historically low real interest rates helped foster increased leverage across a wide range of agents - notably financial institutions and households - and markets. The high degree of leverage, however, limited the ability of borrowers and the financial system to absorb even small shocks, leading to a quick erosion of capital buffers, rapid decline in confidence, and escalation of counterparty risk early on in the crisis. This in turned triggered a liquidity crisis with global ramifications.

Opaqueness of financial transactions and the role of non-banks. Although the originate-todistribute model in the U.S. seemed a good template for risk allocation, it turned out to undermine incentives to properly assess risks and led to a buildup of tail risks. The model also made it much more difficult to know the true value of assets as the crisis unraveled. This lack of understanding quickly turned a liquidity crisis into a solvency crisis. Indeed, the financial turmoil started in those countries where non-banks (including money market funds, investment banks, and special-purpose vehicles) played important roles in financial intermediation. As these non-banks typically did not fall under the formal financial safety net, the risk of runs became more likely.

The complex interdependencies between the regulated and non-regulated parts of the financial system also made responses more difficult than when the financial system consisted primarily of traditional banks (as was the case in many earlier crises). In terms of assets, as it directly involved homeowners in many countries, restructuring also became far more complicated. There are no established best practices for how to deal with large scale households' defaults, and associated moral hazard problems, and equity and distribution issues. Restoring households' balance sheets has proven very complex and prolonged the recovery from the crisis.

High degree of international financial integration. A significant fraction of financial instruments originated in the U.S. was held in other advanced economies and by the official sector in emerging markets. Large cross-border banks, exceeding many countries' GDP in 
size, had extensive, complex exposures in and across many markets. International financial integration more generally had increased dramatically in the decades before the crisis, with global finance no longer involving just a few large players, but many from various markets and different countries. While all this had many benefits, it quickly turned turmoil in a few, large countries into a global crisis. The cross-border linkages across institutions and markets meant disturbances spread quickly, made globally coordinated solutions much more difficult to implement, and worsened the confidence in many ways.

Role of advanced countries. The last episode has been concentrated in advanced economies, contrary to past crises that often took place in emerging markets and developing countries. This meant significant contagion effects from financial institutions in advanced countries to other countries, through both financial and trade channels. After all, the crisis countries were not only home to the main intermediaries of global capital but also the main importers of goods and services. Differences in institutional and economic settings, including the typically larger size of advanced countries' financial systems, required different policy responses, both in terms of macroeconomic and financial policies. While emerging markets, for example, typically tightened monetary policy following a crisis to stem capital outflows, advanced economies were able to resort to expansionary monetary policies to support their financial systems and to boost activity, including through fiscal policy, without considering much the implications of these policies for capital flows. This came with benefits, but also costs, as the necessary restructuring was more easily postponed in the presence of expansionary policies.

\section{Overview of Financial Crises (Part I)}

The forthcoming book starts with a review of financial crises, including their origins and macroeconomic consequences, as well as an overview of the policy responses that countries have tended to resort to when dealing with major banking crises. Claessens and Kose (2013) provide a comprehensive review of the literature on financial crises. They focus on currency crises, sudden stops in capital flows, debt crises, and banking crises. They start with a general overview considering the common elements across different types of crises, including asset

price bubbles, credit booms, buildups of leverage, and large capital inflows. These can of 
course turn into an asset price crash, credit crunch, deleveraging spiral, sudden capital outflow, or sovereign default during a financial crisis.

They also present a brief discussion of the determinants of crises and document the differences in models developed to explain different types of episodes. Over the years, for example, various generations of models have been developed to explain currency crises, whereas the modeling of systemic banking crises is relatively less advanced. They also review the causes identified in empirical work. Although there is much overlap, causes can vary depending on the type of crises. Changes in terms of trade, capital flows and international interest rates, for example, have been found to be important triggers for currency and foreign debt crises, whereas fundamentals, policy failures, domestic and/or external shocks have been shown to be important factors in triggering banking crises.

They discuss the identification of crises in practice, a key challenge for empirical studies. They show using existing databases that, although often associated with emerging markets, crises have been an universal phenomena. Crises also often overlap and come in waves indicating the significant role of global factors in driving these episodes. In addition, they provide a review of the macroeconomic implications of crises. Output losses are almost universal, and consumption, investment and industrial production follow qualitatively similar declines, albeit varying in terms of severity and duration.

The chapter by Laeven and Valencia (2013) offers a detailed database of the starting dates of financial crises as well as on the resolution policies and associated fiscal costs to resolve crises. Their focus is on banking crises, although they also provide information on currency crises and sovereign debt crises. Using their data, they show that countries typically resort to a mix of policies to contain and resolve banking crises, ranging from macroeconomic stabilization to financial sector restructuring policies and institutional reforms.

In addition to offering the most comprehensive and up to date database on banking crises available, Laeven and Valencia (2013) also point out that, despite crises having many commonalities in their origins, many crisis management strategies tried have met with mixed 
success. Those successful crisis resolutions have been characterized by transparency and resoluteness in terms of resolving insolvent institutions, thereby removing uncertainty surrounding the viability of financial institutions. This requires a triage of strong and weak institutions, with full disclosure of bad assets and recognition of losses, followed by the recapitalization of viable institutions and the removal of bad assets and unviable institutions from the system.

While conventional wisdom would have it that advanced economies with their stronger macroeconomic frameworks and institutional settings would have an edge in crisis resolution, the record thus far supports the opposite: advanced economies have been slow to resolve banking crises, with the average crisis lasting about twice as long as in developing and emerging market economies.

With differences in initial shocks and financial system size surely contributing to variations in these outcomes, they suggest that the greater reliance by advanced economies on macroeconomic policies as crisis management tools may delay the needed financial restructuring, prolonging the crisis. This is not to say that macroeconomic policies should not be used to support the broader economy during a crisis. Macroeconomic policies can be the first line of defense. They stimulate aggregate demand and sustain asset prices, thus supporting output and employment, and indirectly a country's financial system. This helps prevent a disorderly deleveraging and gives way for balance sheet repair, buying time to

address solvency problems head on. However, by masking balance sheet problems of financial institutions and borrowers, they may also reduce incentives for financial restructuring, with the risk of dampening growth and prolonging the crisis.

\section{Lessons on Crisis Prevention and Management (Part II)}

The papers in the second part of the forthcoming book provide an elegant analysis of the lessons learned about the warning signals ahead of crises and the management of such episodes. These specially commissioned papers were presented at a conference held at the IMF on September 14, 2012. The first paper by Carmen Reinhart and Kenneth Rogoff is 
based on the keynote address Carmen Reinhart delivered at the conference. The paper makes a convincing case that the current crisis that began with the unraveling of the subprime U.S. mortgage market in 2007 is far from over and is on a scale that has not been seen in advanced economies since the 1930s and World War II debt defaults.

Reinhart and Rogoff (2013) draw four thought-provoking lessons about the current crisis. First, policy makers have often done better at the management of crises than at their prevention. This was also the case for the latest episode. They conjecture this will unlikely change anytime soon. Second, they argue that it is not clear whether there are significant differences between advanced countries and emerging economies with respect to the likelihood of experiencing a crisis. Specifically, they provide a clear reminder that, while in the decades until 2000, crises were the domain of emerging markets, prior to 1940, advanced economies were involved in many crises. Third, both the diagnosis and understanding of the scope and depth of the risks and magnitudes of various debts are still incomplete. Observers tend to forget that domestic and external debt are not created equal, that public debt is different than private debt, and that the stock of debt is usually much larger than currently estimated.

Fourth, they show recurring patterns after global crises where governments have resorted to subtle ways to restructure their debts, rather than default or formal rework repayment terms. The techniques, some of which they call financial repression, include keeping interest rates low, which lowers debt servicing costs and reduces the real value of government debt. Many advanced countries have also used public debt restructurings and conversions of high-yield short-term debt to low-yield long-term debt. Other techniques include directed lending to governments by captive domestic savers such as pension funds, regulation of cross border flows of funds, and a generally tighter relationship between banks and government. The end result is to direct funds, usually at below market rates, to government use that would otherwise go to non-government borrowers. In light of this history, they suggest that it is increasingly likely that there will be debt restructurings and conversions to ease sovereign repayments in some of the stressed economies in Europe. 
The global financial crisis of 2008 caught most economists and policymakers flat-footed, so the search for predictors of such crises has been a major area of research in recent years. The next two papers ask a fundamental question: "what are the best warning signals of financial crises?" Taylor (2013) argues that it is unusually high, sustained rates of credit growth, socalled credit booms that tend to be the main precursor of financial crises. Prior to the global financial crisis, many prominent policymakers and economists focused on the turmoilproducing potential of large current account imbalances in which some major deficit countries, such as the United States, faced a possible "jarring shock" if surplus countries, such as China, ceased financing their deficits. Although such external imbalances can play a role in creating credit booms, his paper documents that it is the credit boom itself, not its source that policymakers should watch for as signs of an impending financial crisis. While economies can have credit booms fueled by external imbalances, most are home-grown credit booms that are unrelated to shifts in the current account.

The third paper by Shin (2013) observes that finding a set of early warning indicators that can flag vulnerability to financial turmoil is an extremely challenging task. Shin focuses on three (sets of) indicators: those based on market prices, the ratio of credit-to-GDP - to assess if credit is expanding excessively, and the behavior of banking sector liabilities, such as monetary aggregates. His results indicate that those based on market prices, such as spreads on credit default swaps, do not give sufficient warning of a crisis. Judging how much the ratio of credit to GDP diverges from its long-term trend is more useful, but it is difficult to determine the long-term trend until after the crisis. He claims that the behavior of bank liabilities has the most promise, simply because banks must borrow to lend. When credit demand is high, banks tend to exhaust their normal, or core, sources of funds and turn to noncore sources, which defining characteristic can vary by institution and financial system. When the ratio of non-core to core liabilities spurts, it is a good indicator that a boom is underway. However, he also notes that it can be difficult to differentiate between core and non-core liabilities before a crisis.

In past global crises, emerging market economies often suffered more than advanced economies did. The reverse was true in the recent global financial crisis. While advanced 
economies suffered - and continue to suffer - emerging market economies, including in Latin America, had a shorter recession and a quicker recovery. In the final paper of this part, De Gregorio (2013) claims that a number of factors contributed to the better performance of emerging markets in the recent financial crisis. Sound macroeconomic policies before the crisis permitted emerging markets in Latin America to undertake sizeable monetary and fiscal stimulus to offset the recession. Countries also allowed their currencies to depreciate sharply, which kept down speculation of further declines.

Financial systems were also generally sound, well capitalized and regulated, and not prone to accumulate the types of risky financial instruments, such as structured securities, that disabled financial systems in advanced economies. Good luck also helped as commodity prices were high before the crisis and, after a sharp contraction in international trade in 2009, rebounded sharply in 2010. In addition, his paper documents that countries maintained a high level of international reserves, which served a dual role - as a form of self-insurance to be tapped in case of a sudden cessation of foreign capital inflow and as a bulwark against currency speculation.

Together with other contributions in the book, these papers provide also some lessons for crisis management, notably for advanced countries today and as regard to banking crises. The response during the ongoing global financial crisis, dominated by advanced economies, heavily relied on the use of monetary and fiscal policies. Advanced economies were generally well placed to resort to such policies without being overly concerned about their impact on the exchange rate, inflation, or public debt. They typically benefit from well-anchored inflation expectations and reserve currencies benefit from flight to quality effects during financial crises. Emerging market economies, on the other hand, often do not have the fiscal space or the access to (external) finance to support accommodative fiscal policy, while excessive monetary expansion quickly translates into inflation and large declines in the value of the currency, impairing balance sheets further in the presence of currency mismatches.

Advanced countries also used a much broader range of policy measures compared to past episodes, including unconventional asset purchases and guarantees, and significant fiscal 
stimulus packages. These policies were combined with substantial government guarantees on non-deposit bank liabilities and ample liquidity support for banks, often at concessional penalty rates and at reduced collateral requirements. Liquidity support has been particularly large in the euro area, indicating the significant role played by the eurosystem in managing the crisis, compensating in part for the absence of a common fiscal authority.

The lack of deeper restructuring also reflected a limited nature of tools available. Initially, countries' response to the crisis was limited to tools that were readily available and did not require institutional reforms or parliamentary approval. For example, many advanced countries did not have the tools in place to resolve complex financial institutions, including non-banks, prior to the crisis. Restructuring often involved budgetary approval for government programs to purchase assets or recapitalize financial institutions, causing delays or inadequate funds. Given the lack of cross-border resolution frameworks and often complex burden sharing challenges, interventions in ailing institutions with international spillovers were often poor.

It is not just economic conditions, however, but also political economy considerations that can favor the use of such policies over deep financial restructuring using tools such as bank recapitalizations. The latter are generally seen by the public as enriching bankers. Accommodative monetary policy, although less targeted to the underlying problems, is more likely to harbor broad based support: low interest rates will support asset prices for investors and house prices for home owners, and will lower the debt burden for mortgage holders and other debtors. Taken together, as the papers stress, these actions have mitigated the financial turmoil, contained the crisis, and avoided an even sharper contraction in economic activity. However, they also have discouraged more active financial restructuring.

The net result appears to be that much of the cost of this crisis has been transferred to the future, in the form of higher public debt and possibly a dampened economic recovery due to residual uncertainty about the health of banks and continued high private sector indebtedness. The lingering effects stemming from bad assets and uncertainty about the health of financial institutions risk prolonging the crisis and depressing growth for an extended period of time. 
The broader lesson of this set of papers thus is that macroeconomic stabilization policies should supplement and support, but not displace or delay necessary financial restructuring.

\section{Short-Run Effects: Crises, Recessions and Recoveries (Part III)}

Part III of the forthcoming book considers the short-run effects of financial crises in terms of the evolution of macroeconomic and financial variables. The papers in this part show that recessions associated with financial crises tend to be unusually severe and their recoveries typically slow (Terrones, Scott, and Kannan, 2013). The recent bout of crises in particular took a very heavy toll on the real economy. However, as Claessens, Kose, and Terrones (2013) show, this might not have been a surprising outcome. Recessions associated with financial crises tend to be unusually severe, resulting in much larger declines in real economic activity, and their recoveries tend to be slow. Similarly, globally synchronized recessions are often long and deep, and recoveries from these recessions are generally weak.

These studies also consider the effectiveness of policies during crises. Countercyclical monetary policy can help shorten recessions, but its effectiveness is limited in financial crises. By contrast, expansionary fiscal policy seems particularly effective in shortening recessions associated with financial crises and boosting recoveries. However, its effectiveness is a decreasing function of the level of public debt. These findings suggest the current financial crisis is likely to have unusually long and severe impacts, with the recovery sluggish. However, strong countercyclical policy action, combined with the restoration of confidence in the financial sector, could help move the recovery forward.

Claessens, Kose and Terrones (2013) also present a brief analysis of the similarities and differences between the current crisis and previous episodes. They show that the buildup to the financial crisis has four major features similar to earlier episodes: First, asset prices rapidly increased in a number of countries before the crisis. Second, a number of key

economies experienced episodes of credit booms ahead of the crisis. Third, there was a dramatic expansion in marginal loans, particularly in the mortgage markets of several advanced economies, which together led to a sharp increase in systemic risk. Fourth, the 
supervision of financial institutions failed to keep up with developments. These factors combined sharply increased the risk of a financial crisis.

They also claim that some four new dimensions played important roles in the severity and global scale of the crisis that included surprising disruptions and breakdowns of several markets in the fall of 2008. First, there was a widespread use of complex and opaque financial instruments. Second, the interconnectedness among financial markets, nationally and internationally, with the United States at the core, had increased dramatically in a short time period. Third, the degree of leverage of financial institutions accelerated sharply. Fourth, the household sector played a central role. These new elements combined to create unprecedented complications in the fall of 2008 and resulted in the global financial crisis.

\section{Medium-term Effects: Economic Growth (Part IV)}

Part IV of the forthcoming book considers the more medium-term effects of financial crises on the real economy. Balakrishnan et al. (2013) examine the medium-term output performance following 88 banking crises that occurred over the past four decades across a wide range of economies, as well as the behavior of world output following major financial crises going back to the $19^{\text {th }}$ century. They find that output tends to be depressed substantially and persistently following banking crises, with no rebound on average to the pre-crisis trend over the medium term. Growth does, however, eventually return to its pre-crisis rate for most economies. The depressed output path tends to result from long-lasting reductions of roughly equal proportion in the employment rate, the capital-to-labor ratio, and total factor productivity. In the short term, the output loss is mainly accounted for by total factor productivity losses, but, unlike the employment rate and capital-to-labor ratio, the level of total factor productivity recovers somewhat to its pre-crisis trend over the medium term. In contrast, capital and employment suffer enduring losses relative to trend.

Surprisingly, a large number of recoveries from crises occur in the absence of credit growth. This is what Abiad, Dell'Ariccia, and Li (2013) label as credit-less recoveries. They show that such recoveries are not rare: about one out of five recoveries is creditless, but average growth 
during these episodes is about a third lower than during normal recoveries. Aggregate and sectoral data suggest that impaired financial intermediation is the culprit. Creditless recoveries are more common after banking crises and credit booms. Furthermore, sectors more dependent on external finance grow relatively less and more financially dependent activities (such as investment) are curtailed more during creditless recoveries.

\section{Policy Measures to Prevent Booms, Mitigate Busts, and Avoid Crises (Part V)}

Part V of the forthcoming book studies the effectiveness of policies in curbing credit booms and bust, with the aim to prevent or manage financial crises. The first set of papers studies the effectiveness of macroeconomic and macroprudential policies to reduce the risks associated with (real estate) credit booms (Dell'Ariccia, Igan, Laeven and Tong, 2013; Crowe, Dell'Ariccia, Igan, and Rabanal, 2013). Both papers find that well-targeted macroprudential

policies, such as caps on loan to value ratios and capital requirements that increase during boom times, and to a lesser extent macroeconomic policies, if properly designed, have some success in curbing excessive credit growth and mitigating the consequences of credit and asset prices busts.

Financial sector policies need not be used in isolation to address financial sector problems, but can be complemented with and supported by macroeconomic policies. This is also evident in the remaining two papers in this part of the book. Laeven and Valencia (2013) show that direct fiscal costs to support the financial sector were smaller during recent crises as opposed to earlier crises as a consequence of swift policy actions and significant indirect support from expansionary monetary and fiscal policy, the widespread use of guarantees on liabilities, and direct purchases of assets (such as mortgage securities by central banks). And Baldacci, Gupta, and Mulas-Granados (2013) show that timely countercyclical fiscal measures can contribute to shortening the length of crisis episodes by stimulating aggregate demand, with fiscal expansions that rely mostly on measures to support government consumption more effective in shortening the crisis duration than those based on public investment or income tax cuts. 
Of course, while these policies reduced the real impact of crises, they currently increase the burden of public debt and the size of government contingent liabilities, raising concerns about fiscal sustainability in some countries. In fact, the results in Baldacci et al (2013) do not hold for countries with limited fiscal space where fiscal expansions are prevented by funding constraints. The composition of countercyclical fiscal responses matters as well for output recovery after a crisis, with public investment yielding the strongest impact on growth. These results suggest a potential trade-off between short-run aggregate demand support and medium-term productivity growth objectives in fiscal stimulus packages adopted in distress times, with the tradeoff affected by the depth of financial restructuring.

\section{Policy Measures to Mitigate Impact of Crises and How to Restructure (Part VI)}

The final part (Part VI) of the forthcoming book considers policies to deal with the restructuring of banks as well as debt overhang in the public or private sectors of the economy, specifically the restructuring of sovereign debt and household debt. On bank restructuring, Landier and Ueda (2013) argue that the optimal design of a bank restructuring program depends on the payoffs and incentives for the various key stakeholders, including shareholders, debt holders, and government, and that the benefits and costs of financial sector interventions should be compared to those of alternative interventions the government could do to support the economy. At the same time, time is of the essence.

Claessens et al. (2013) compare the policy choices in recent and past crises and argue that the overall asset restructuring and balance-sheet repair of financial institutions this time around are much less advanced than they should be at this stage and that moral hazard has increased. Consequently, vulnerabilities in the global financial system remain considerable and continue

to threaten the sustainability of the recovery. They call for more aggressive asset restructuring to complete the much-needed financial sector repair and reform process.

In terms of household debt restructuring, the historically high levels of household debt in many countries currently facing financial crisis have heightened demands for government interventions. If unaddressed, household debt distress can be a drain on the economy and even 
lead to social unrest. Well-designed and well executed government interventions may be more efficient than leaving debt restructuring to the market place and standard court-based resolution tools alone. Laeven and Laryea (2013) make the case for government interventions in household debt restructuring. They propose, in addition to targeted legal reforms, a template for government-supported household debt restructuring programs designed to reverse nonperforming loans, which could be adapted to individual country circumstances.

The case for household debt restructuring is also made in the paper by Igan, Leigh, Simon, and Topalova (2013), who show that housing busts and recessions preceded by larger run-ups in household debt tend to be more severe and protracted. These patterns are consistent with the predictions of recent theoretical models. Based on case studies, they show that government policies can help prevent prolonged contractions in economic activity by addressing the problem of excessive household debt. In particular, bold household debt restructuring programs such as those implemented in the United States in the 1930s and in Iceland recently can significantly reduce debt repayment burdens and the number of household defaults and foreclosures. Such policies can therefore help avert self-reinforcing cycles of household defaults, further house price declines, and additional contractions in output.

Finally, in terms of sovereign debt restructuring, Das, Papaioannou, and Trebesch (2013) provide a comprehensive survey of pertinent issues, based on a newly constructed database covering 185 debt exchanges with foreign banks and bondholders since the 1950s, and 447 bilateral debt agreements with the Paris Club. They present new stylized facts on the outcome and process of debt restructurings, including on the size of haircuts, creditor participation and legal aspects, and discuss ongoing debates on crisis resolution mechanisms, credit default swaps, and the role of collective action clauses. Their paper shows as well that rapid restructuring can have many benefits. 


\section{References}

Abiad, A., G. Dell'Ariccia, B. Li, 2013, "What Have We Learned about Creditless Recoveries?," in S. Claessens, M. A. Kose, L. Laeven, and F. Valencia, eds., Financial Crises, Consequences, and Policy Responses, forthcoming, IMF.

Abiad, A., R. Balakrishnan, P. K. Brooks, D. Leigh, and I. Tytell, 2013, "What's the Damage: Medium-term Output Dynamics after Financial Crises," in S. Claessens, M. A. Kose, L. Laeven, and F. Valencia, eds., Financial Crises, Consequences, and Policy Responses, forthcoming, IMF.

Baldacci, E., S. Gupta, and C. Mulas-Granados, 2013, "How Effective is Fiscal Policy Response in Financial Crises?," in S. Claessens, M. A. Kose, L. Laeven, and F. Valencia, eds., Financial Crises, Consequences, and Policy Responses, forthcoming, IMF.

Claessens, S., and M. A. Kose, 2013, "Financial Crises: Explanations, Types, and Implications" in S. Claessens, M. A. Kose, L. Laeven, and F. Valencia, eds., Financial Crises, Consequences, and Policy Responses, forthcoming, IMF.

Claessens, S., C. Pazarbasioglu, M. Dobler, F. Valencia, O. Nedelescu, and K. Seal, 2013, "Crisis Management and Resolution: Early Lessons from the Financial Crisis," in S. Claessens, M. A. Kose, L. Laeven, and F. Valencia, eds., Financial Crises, Consequences, and Policy Responses, forthcoming, IMF.

Claessens, S., M. A. Kose, and M. E. Terrones, 2013, "The Recent Global Financial Crisis: How Similar? How Different? How Costly?," in S. Claessens, M. A. Kose, L. Laeven, and F. Valencia, eds., Financial Crises, Consequences, and Policy Responses, forthcoming, IMF.

Crowe, C., G. Dell'Ariccia, D. Igan, and P. Rabanal, 2013, "Policies for Macrofinancial Stability: Managing Real Estate Booms and Busts,” in S. Claessens, M. A. Kose, L. Laeven, and F. Valencia, eds., Financial Crises, Consequences, and Policy Responses, forthcoming, IMF.

Das, U. S., 2013, "Restructuring Sovereign Debt: Lessons from Recent History," in S. Claessens, M. A. Kose, L. Laeven, and F. Valencia, eds., Financial Crises, Consequences, and Policy Responses, forthcoming, IMF.

De Gregorio, J., 2013, " Resilience in Latin America: Lessons from Macroeconomic Management and Financial Policies," in S. Claessens, M. A. Kose, L. Laeven, and F. Valencia, eds., Financial Crises, Consequences, and Policy Responses, forthcoming, IMF.

Dell'Ariccia, G., D. Igan, L. Laeven, and H. Tong, 2013, "Policies for Macrofinancial Stability: Dealing with Credit Booms and Busts," in S. Claessens, M. A. Kose, L. 
Laeven, and F. Valencia, eds., Financial Crises, Consequences, and Policy Responses, forthcoming, IMF.

Igan, D., D. Leigh, J. Simon, and P. Topalova, 2013, "Dealing with Household Debt," in S. Claessens, M. A. Kose, L. Laeven, and F. Valencia, eds., Financial Crises, Consequences, and Policy Responses, forthcoming, IMF.

Kannan, P., A. Scott, and M. E. Terrones, 2013, "From Recession to Recovery: How Soon and How Strong," in S. Claessens, M. A. Kose, L. Laeven, and F. Valencia, eds., Financial Crises, Consequences, and Policy Responses, forthcoming, IMF.

Laeven, L., and F. Valencia, 2013, "Resolution of Banking Crises: The Good, the Bad, and the Ugly," in S. Claessens, M. A. Kose, L. Laeven, and F. Valencia, eds., Financial Crises, Consequences, and Policy Responses, forthcoming, IMF.

Laeven, L., and F. Valencia, 2013, "Systemic Banking Crises" in S. Claessens, M. A. Kose, L. Laeven, and F. Valencia, eds., Financial Crises, Consequences, and Policy Responses, forthcoming, IMF.

Laeven, L., and T. Laryea, 2013, "Principles of Household Debt Restructuring," in S. Claessens, M. A. Kose, L. Laeven, and F. Valencia, eds., Financial Crises, Consequences, and Policy Responses, forthcoming, IMF.

Landier, A., and K. Ueda, 2013, "The Economics of Bank Restructuring: Understanding the Options," in S. Claessens, M. A. Kose, L. Laeven, and F. Valencia, eds., Financial Crises, Consequences, and Policy Responses, forthcoming, IMF.

Reinhart, C. M., and K. S. Rogoff, 2009, This Time is Different: Eight Centuries of Financial Folly, Princeton Press.

Reinhart, C. M., and K. S. Rogoff, 2013, "Financial and Sovereign Debt Crises: Some Lessons and Those Forgotten," in S. Claessens, M. A. Kose, L. Laeven, and F. Valencia, eds., Financial Crises, Consequences, and Policy Responses, forthcoming, IMF.

Shin, H. S., 2013, "Procyclicality and the Search for Early Warning Indicators," in S. Claessens, M. A. Kose, L. Laeven, and F. Valencia, eds., Financial Crises, Consequences, and Policy Responses, forthcoming, IMF.

Taylor, A. M., 2013, "External Imbalances and Financial Crises," in S. Claessens, M. A. Kose, L. Laeven, and F. Valencia, eds., Financial Crises, Consequences, and Policy Responses, forthcoming, IMF. 